\title{
Implicancias Estructurales y Fisiológicas de la Célula Bacteriana en los Mecanismos de Resistencia Antibiótica
}

\author{
Structural and Physiological Implications of Bacterial Cell in Antibiotic Resistance Mechanisms
}

Claudia Troncoso ${ }^{1,2,3}$; Mónica Pavez ${ }^{1,2}$; Andrés Santos ${ }^{1,2}$; Rodrigo Salazar ${ }^{1} \&$ Leticia Barrientos $^{1,2}$

TRONCOSO, C.; PAVEZ, M.; SANTOS, A.; SALAZAR, R. \& BARRIENTOS, L. Implicancias estructurales y fisiológicas de la célula bacteriana en los mecanismos de resistencia antibiótica. Int. J. Morphol., 35(4):1214-1223, 2017.

RESUMEN: La alta capacidad de adaptación de las bacterias a ambientes hostiles ha permitido el desarrollo de resistencia a antibacterianos, causando problemas de impacto mundial en la salud hospitalaria y de la comunidad, limitando las opciones terapéuticas lo que afecta el control de enfermedades, elevando las tasas de morbi-mortalidad. Esta capacidad de resistencia es mediada por factores estructurales y fisiológicos de las bacterias que actúan a diferentes niveles tanto extracelular como intracelular. A niveles extracelulares se destaca la capacidad de las poblaciones bacterianas en la formación de biopelículas y la regulación de señales celulares quorum sensing, permitiendo la evasión de la acción antibiótica. A nivel de envoltura celular se destaca el funcionamiento y comportamiento de la pared celular y de la membrana celular, principalmente por medio de la regulación de la expresión de canales de entrada o porinas y/ o bombas de expulsión que impiden el acceso o inducen la salida de antibióticos; otros mecanismos integran la modificación de la actividad de drogas por medio de la hidrólisis o modificación del sitio activo del fármaco. A nivel intracelular, las bacterias pueden cambiar los procesos de óxido/reducción, modificar los sitios objetivos del antibiótico e inactivar los grupos transfer, y modificar las subunidades ribosomales afectando la acción de los antibióticos que inhiben la síntesis de proteínas. A esto se añaden las modificaciones en la expresión génica y del código genético, que regula todos los anteriores, y es capaz de generar cambios adaptativos, resistencia a fármacos y desinfectantes, entre otros. La presente revisión tiene como objetivo describir las implicancias estructurales y fisiológicas de la célula bacteriana en los mecanismos de resistencia antibiótica considerando la organización estructural y fisiológica involucrada en los principales mecanismos de resistencia a antibióticos presentes en bacterias de importancia clínica que conllevan a fallas terapéuticas con alto costo en salud humana.

PALABRAS CLAVE: Célula bacteriana; Resistencia; Antibióticos.

\section{INTRODUCCIÓN}

Las bacterias presentan una alta capacidad adaptativa al medio donde se desarrollan, lo que les permite ajustarse a condiciones adversas y garantizar así su sobrevivencia. Entre estos fenómenos adaptativos se destaca la resistencia a los antimicrobianos y a otras sustancias tóxicas como desinfectantes (Erickson et al., 2015).

La resistencia antibiótica puede definirse como la capacidad de un microorganismo para sobrevivir en presencia de un compuesto tóxico (antibiótico o antiséptico), permitiendo que las bacterias se multipliquen en presencia del fármaco (Lebeaux et al., 2014). Esta capacidad de resistencia bacteriana cobra importancia a nivel mundial en el área de salud pública por su efecto en el control de enfermedades y su impacto en las limitaciones terapéuticas, restringiendo la capacidad de fármacos disponibles (Da Silva \& Domíngues, 2016), prolongando estadías de hospitalización, aumentando costos médicos e incluso generando mortalidad (OMS, 2017).

El amplio uso de antibióticos ha creado una presión selectiva que se ha reconocido como la base de la emergencia de resistencia adaptativa (Frye \& Jackson, 2013). Así, esta resistencia antibiótica es el resultado de modificaciones estructurales y características funcionales propias del microorganismo o características adquiridas en respuesta al estrés sufrido por una presión selectiva (Borges et al., 2016).

Las bacterias han adoptado diversos mecanismos de evasión a la acción de los antibióticos, ya sea impidiendo el

\footnotetext{
${ }^{1}$ Laboratorio de Biología Molecular Aplicada. Centro de Excelencia en Medicina Traslacional. Temuco, Chile.

${ }^{2}$ Núcleo Científico y Tecnológico en Biorecursos (BIOREN), Universidad de La Frontera, Temuco, Chile.

${ }^{3}$ Facultad de Ciencias de la Salud, Universidad Autónoma de Chile, Temuco - Chile.
} 
acceso de ellos a los sitios blanco por reducción de permeabilidad de membranas, incrementando la expresión de bombas de expulsión, degradación e inactivación enzimática o modificación de drogas, y/o cambios de sitios objetivos de antibióticos (Lebeaux et al.; Zhou et al., 2015). Si estos mecanismos de defensa a antimicrobianos son insuficientes, muchas bacterias pueden utilizar otros medios de defensa que incluyen alteración intracelular y regulación de genes (Zhou et al.).

En la $68^{\mathrm{a}}$ Asamblea Mundial de la Salud, realizada en Ginebra (Suiza), en mayo del año 2015 y organizada por la Organización Mundial de la Salud, se propuso aplicar medidas globales para mejorar la comprensión y toma de conciencia del manejo de la resistencia bacteriana con la finalidad de lograr nuevas medicinas y herramientas diagnósticas, disposición de vacunas y otras intervenciones que contribuyan a mejorar los tratamientos y prevención de infecciones bacterianas (OMS, 2015; Krishnamurthy et al., 2016).

Como una forma de contribuir al conocimiento y al control de la resistencia bacteriana, a continuación se describen las principales características de los mecanismos de resistencia presentes en las bacterias a nivel morfológico y funcional, comenzando por los cambios que ocurren a nivel extracelular, luego las modificaciones de pared celular y membranas, para posteriormente continuar con los cambios intracelulares y genéticos (Fig. 1).

\section{Mecanismos de resistencia bacteriana a nivel extracelular}

Formación de biopelículas. Las biopelículas se describen como agregaciones estructuradas de células bacterianas, encerradas en una matriz extracelular auto sintetizada conformada por diferentes macromoléculas (Sager et al., 2015). Esta propiedad favorece el desarrollo de comunidades sésiles de microorganismos que se unen irreversiblemente a un sustrato o co-agregado. Generalmente, estas células están incrustadas en una matriz de sustancias poliméricas extracelulares altamente hidratadas (EPSs- cuyas siglas en inglés corresponden a extracellular polymeric substances) útiles para la agregación, estructura y mantenimiento del estilo de vida de la comunidad bacteriana (Jayaraman \& Wood, 2008). El desarrollo de la biopelícula es un proceso complejo, que se inicia con la adherencia de bacterias planctónicas a una superficie con la consiguiente formación de microcolonias (Donné \& Dewilde, 2015), la unión inicial es impulsada por las fuerzas débiles de Van der Waals y pue-

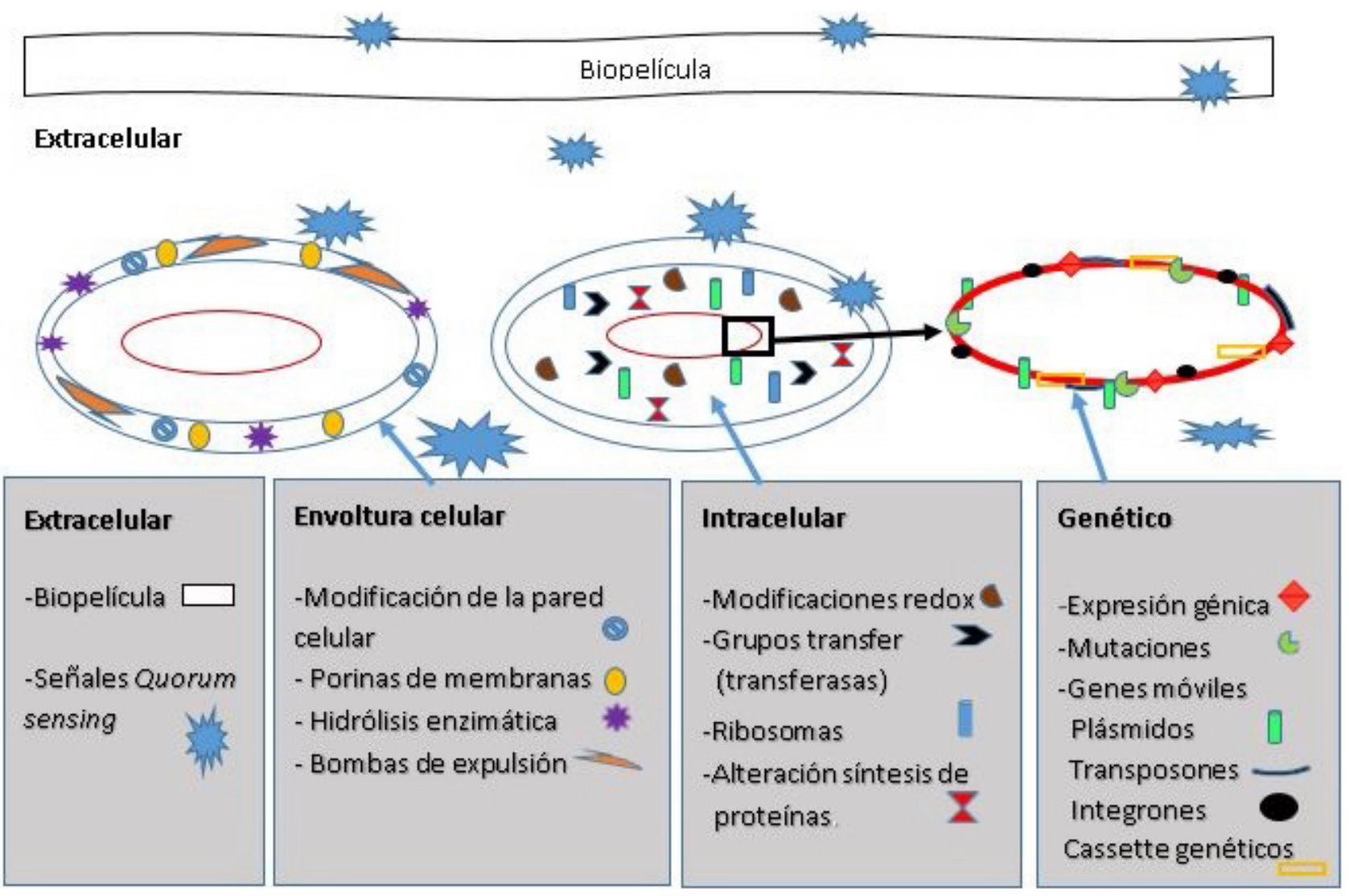

Fig. 1. Organización estructural y fisiológica de los mecanicos de resistencia bacteriana 
de involucrar a los flagelos bacterianos (Belas, 2014). La expresión de las estructuras de adhesión celular, incluyendo el pili, está sobre regulada para permitir una interacción permanente más fuerte. Una vez unidas, las bacterias comienzan a proliferar y secretar una matriz extracelular compuesta de polisacáridos, ácidos nucleicos y proteínas quedando protegidas de factores nocivos del ambiente (Billings et al., 2015; Santajit \& Indrawattana, 2016). La matriz extracelular que encapsula a la biopelícula crea una barrera de difusión física (Jefferson et al., 2005; Singh et al., 2010), que protege a la comunidad bacteriana de la respuesta inmune del hospedador, dificulta o impide la acción antibiótica y otorga alta adherencia del microorganismo a una determinada superficie (Sager et al.). La viscosidad de la capa pegajosa exterior impide la difusión de los antibióticos a las capas más profundas de la biopelícula. Los componentes cargados negativamente de la matriz extracelular repelen a los antibióticos cargados positivamente tales como los aminoglicósidos (Cos et al., 2010). La matriz extracelular también alberga enzimas, tales como $\beta$-lactamasas, que actúan destruyendo la integridad estructural de los antibióticos (Donné \& Dewilde). Este estilo de vida bacteriano es una adaptación particularmente importante para crecer como parte de una comunidad sésil, que imita a un organismo multicelular integrado con su propio ciclo de desarrollo, el comportamiento cooperativo entre las especies, y la gestión coordinada utilizando moléculas de detección señal quorum sensing para comunicarse entre ellos. La biopelícula ofrece protección de las agresiones fisicoquímicas, luz ultravioleta, metales pesados, acidez del medio, cambios de hidratación y salinidad, fagocitosis y capacidad de evadir la agresión de los antibióticos (Jayaraman \& Wood; Lebeaux et al.). Se ha demostrado que las biopelículas tienen una alta persistencia una vez que se establecen las infecciones y por lo tanto son responsable de muchos procesos infecciosos crónicos (Peyyala \& Ebersole, 2013). La baja capacidad de penetración de los antimicrobianos en la biopelícula es el principal obstáculo para el tratamiento antibiótico de las infecciones, generando un fenotipo con capacidad de resistencia a altas concentraciones de antimicrobianos y modulación de los mecanismos de defensa del hospedador, incluso cuando son totalmente susceptibles a tales agentes en condiciones planctónicas (Peterson et al., 2015). Este mecanismo de resistencia se ha denominado "biofilm bacteriano recalcitrante a antibióticos", el cual es un proceso reversible y no heredado, y desaparece cuando se interrumpe la biopelícula y las bacterias vuelven a un estado planctónico (Lebeaux et $a l$. ). La tolerancia antibiótica no se fundamenta solo en una barrera que impide el paso del antibiótico. Estudios en tetraciclina marcada realizados por Lebeaux et al., señalan que a las seis horas de administrado el antibiótico, éste alcanzaba importantes niveles en la población bacteriana presente en biopelículas. Se presume que la matriz de polisacáridos retrasa el tiempo de incorporación del fármaco, facilitando la adaptación bacteriana al medicamento. La asociación de una barrera que reduce la velocidad de difusión del fármaco y la presencia de otros elementos como enzimas hidrolizantes pueden actuar sinérgicamente, especialmente si estas enzimas degradan más rápido que lo que se difunden los antibióticos (Santajit \& Indrawattana, 2016). Es necesario considerar que muchos antibióticos son más eficaces en bacterias metabólicamente activas y en crecimiento. La biopelícula genera un ambiente bajo en $\mathrm{pH} \mathrm{y}_{2}$, alto en $\mathrm{CO}_{2}$ y limitado en agua disponible, dificultando la acción de fármacos antimicrobianos convencionales (Santajit \& Indrawattana, 2016). La falta de nutrientes o anoxia de estos microambientes puede antagonizar los efectos de los antibióticos, como sucede con los $\beta$-lactámicos, que se dirigen a la pared celular bacteriana y son eficaces sólo contra bacterias en crecimiento activo en fases de división celular (Lewis, 2001). Lebaux et al. (2014), correlacionaron de forma inversamente proporcional los efectos de los $\beta$ lactámicos en las biopelículas de Pseudomonas aeruginosa con la actividad metabólica de éstas. La comunicación quorum-sensing es uno de los mecanismos propuestos en el desarrollo y organización de la biopelícula, como es el caso de los sistema quorum sensing LasR/LasI y RhlR/ RhlI que facilita la formación de biopelícula (Krishnamurthy et al.) favoreciendo así la evasión de la acción de los antimicrobianos (Zhou et al.).

Sistema quorum sensing (QS). Mecanismo adoptado por comunidades bacterianas relacionado con la densidad de población, o por señales simples producidas por bacterias. El primero se reconoce como quorum sensing señal, el otro corresponde a un sistema autoinductor y es utilizado en comunicaciones célula-célula o por señales producidas por bacterias en distintos estados de crecimiento que les permite regular la expresión génica independiente de la densidad celular. Un ejemplo es el Indol producido por E. coli en la fase estacionaria de crecimiento, el cual actúa como una señal, capaz de modificar funciones celulares, tales como patogenicidad, movilidad, atenuar adherencia y cambios de la expresión génica (Jayamaran \& Wood, 2008; LaSarre \& Federle, 2013). Muchas de estas señales se generan como respuesta al estrés ambiental incluido el provocado por antibacterianos (Gill et al., 2015). El sistema QS está presente en bacterias de una misma especie o entre especies distintas y es regulado por diferentes señales químicas que son sintetizadas y secretadas por varias bacterias (Jayamaran \& Wood, 2008; Que et al., 2013). Un ejemplo de este sistema asociado a resistencia a antibacterianos se observa en Streptococcus pneumoniae, el cual en medios de cultivo in vitro, regula la expresión génica de péptidos antibacterianos aumentando su producción cuando las concentraciones de señales moleculares se incrementan sobre concentraciones 
críticas (Jayamaran \& Wood, 2008). Estudios realizados por Que et al. en Pseudomonas aeruginosa reportan que por medio de señales QS la bacteria es capaz de inducir resistencia a antimicrobianos cuando coloniza pacientes con fibrosis quística, atribuyendo la secreción de la molécula volátil 2'aminoacetofenona (2 AA), la cual también es la responsable del olor dulce a uvas, característico de esta bacteria.

Aunque existen las líneas de defensa anteriormente descritas, una variedad de antimicrobianos pueden alcanzar con éxito diferentes sitios de la bacteria y ejercer su actividad. En respuesta, las células bacterianas harán todo lo posible para competir contra estos agentes, empleando estrategias desde la envoltura celular.

\section{Mecanismos de resistencia a nivel de envoltura celular.}

En esta categoría se han propuesto cuatro mecanismos generadores de resistencia: impermeabilidad de membranas, porinas, bombas de expulsión e hidrólisis enzimática. A continuación se detalla como ocurren estos procesos.

Impermeabilidad de membranas. Las bacterias están rodeadas por una envoltura celular que constituye una eficiente barrera selectiva, cumpliendo funciones reguladoras del ingreso de sustancias desde el medio externo al interior de la célula y viceversa (Borges et al.). La envoltura celular es crucial para el mantenimiento de la forma celular y el intercambio de nutrientes o moléculas de señalización; está conformada por la pared celular bacteriana y la membrana plasmática presente en Gram positivos y Gram negativos y membrana externa exclusiva de Gram negativos (Martínez \& Sánchez, 2007). Estas estructuras son sitios objetivos importantes para muchos compuestos antimicrobianos, incluyendo betalactámicos, glicopéptidos, fosfomicina, daptomicina, polimixina y antibióticos ionóforos. Las alteraciones del sitio objetivo del fármaco, por ejemplo, la modificación del extremo terminal del peptidoglicano, impide la unión del fármaco vancomicina al sitio diana, o la degradación de $\beta$-lactámico que inutiliza el antibiótico, permitiendo la síntesis de la pared celular, generando resistencia antibiótica (Sheldon, 2005), o bien puede ocurrir debido a cambios en la pared celular o en la conformación de la membrana, o por penetración limitada de los antimicrobianos a través de estas barreras físicas (Borges et al.).

La envoltura celular no es sólo un sitio diana de acción antibiótica, es también la vía de ingreso de diversos compuestos al interior de la célula, entre ellos los antibióticos. Para que un antibiótico sea eficaz debe alcanzar una concentración suficientemente alta en sus sitios diana, para ello una gran variedad de antibióticos deben atravesar las barreras físicas de la envoltura celular (Martínez \& Sánchez). Las bacterias alteran estas vías de ingreso por medio de cambios conformacionales de las membranas celulares, impidiendo el ingreso del fármaco, mecanismos que se revisan a continuación.

Porinas de membranas. La restricción del acceso de los antibióticos mediado por porinas de membrana es uno de los mecanismos de resistencia de la envoltura celular más comunes; actúan evitando el ingreso del antimicrobiano, por ende, reduciendo su acción a nivel citoplasmático o de la envoltura celular (Zhou et al.). Las porinas son estructuras proteicas que determinan la permeabilidad de la membrana externa (Delcour, 2009) por medio de canales abiertos al tránsito de agua, facilitando el transporte pasivo de moléculas hidrofílicas (Pagès et al., 2008). Por medio de canales hidrofílicos se selecciona el ingreso de partículas según carga y tamaño de éstas, permitiendo la difusión de un elevado número de moléculas incluyendo antibióticos (Delcour). Se encuentran presentes en la membrana externa de bacterias Gram negativas, siendo su estructura diferente a las proteínas de membrana. Están conformadas de dos hojas b antiparalelas con secuencia polar, siendo la proteína extremadamente resistente a detergentes (Cowan et al., 1992). Se clasifican de acuerdo a su actividad (en canales específicos o inespecíficos y poro selectivo), según su estructura funcional (monomérica o trimérica) y su según regulación y expresión (Pagès et al.). Como ejemplo funcional de porinas se destacan en E. coli tres porinas, PhoeE, OmpF- OmpC. La primera (PhoE) selecciona moléculas aniónicas como fosfatos y es regulada por la necesidad de fosfatos en la célula. Las proteínas OmpF (homóloga OmpK35) y OmpC (homóloga OmpK36), son más abundantes en enterobacterias, con mayor selectividad para moléculas catiónicas y regulación menos específica influyendo en la osmolaridad, $\mathrm{pH}$, temperatura y nutrientes (Cowan et al.). Ambas proteínas tienen $60 \%$ de similitud en su estructura y difieren en su potencial eléctrico (García-Fernández et al., 2010). Cambios en la funcionalidad de las porinas pueden alterar la permeabilidad de los fármacos evitando el efecto antibacteriano (Santajit \& Indrawattana, 2016). Los canales de porinas son la vía de entrada de antibióticos $\beta$-lactámicos y floroquinolonas (Pagès et al.). La modificación de las porinas, afecta principalmente a esta línea de antibióticos (Picão et al., 2008), incluyendo también carbapenémicos y cefalosporinas (Findlay et al., 2012). La disfunción de las porinas es favorecida por la exposición a los antibióticos debido a que la terapia antibiótica favorece respuestas adaptativas, reflejadas en cambios fenotípicos que regulan la función de las porinas. Un ejemplo es la pérdida de la actividad de porinas OmpC en bacterias Gram negativas, impidiendo el ingreso de antibióticos $\beta$-lactámicos, favoreciendo la resistencia antibiótica y la apertura de porinas inactivas, con el consiguiente cambio en el transporte de moléculas hacia el interior de la célula, incluso activando bom- 
bas de expulsión (Pagès et al.), generando efecto sinérgico entre estos mecanismos, por consecuencia resistencia a múltiples antimicrobianos (Santajit \& Indrawattana, 2016).

Bombas de expulsión. Otro mecanismo presente a nivel de envoltura celular y que permite remover antibióticos desde el compartimiento intracelular es a través de bombas de expulsión, ubicadas en la membrana citoplasmática de bacterias Gram positivos y en el espacio intermembrana de Gram negativos (Beceiro et al., 2013; Santajit \& Indrawattana, 2016).

Las bombas de expulsión son proteínas de membrana que facilitan la salida de sustancias hacia el exterior de la célula (Chandra et al., 2017). Estos sistemas cumplen un rol fundamental en el metabolismo y en la actividad celular, teniendo la propiedad de transportar hacia el exterior una amplia variedad de sustancias, incluyendo antibióticos, lo que impide obtener concentraciones óptimas para su acción, generando resistencia antibiótica. Algunas otorgan selectividad específica a un tipo de sustancias o drogas y otras a varias simultáneamente (Sheldon, 2005; Tegos et al., 2011). Según la fuente de energía y sus usos, se consideran dos grandes grupos de sistemas de expulsión (Zhou et al.), el primero utiliza la energía del ATP y expulsión por hidrólisis, el cual incluye a la super familia ABC (ATP Binding Casette); el otro grupo utiliza la fuerza móvil de protones y por consiguiente transporte secundarios o antiporte protón/droga, la energía del potencial electroquímico de la membrana potencia el flujo de salida de sustancia tóxicas (Li et al., 2015a; Zhou et al.). En este segundo grupo se incluyen cinco familias: i) familia de expulsión de múltiples antimicrobianos (MATE, Multimicrobiane Toxical Extrusion), ii) super familia facilitadora principal (MFS, Major Facilitator Super Family), iii) la familia división celular nodulación resistente (RND, Resistance Nodulations Cell Division), iv) la pequeña familia de resistencia a múltiples fármacos (SMR, Small Multidrug Resistance) y v) familia transporte multidroga endosomal (MET, Multidrug Endosomal Transporter), (Li \& Nikaido, 2009; Tegos et al.; Li et al., 2015a; Zhou et al.). Todos estos sistemas se encuentran presentes en bacterias Gram positivo y Gram negativo, excepto los RND exclusivos de Gram negativo (Li et al., 2015a; Zhou et al.; Masi et al., 2017). El sistema de flujo de transporte RND, está conformado por una estructura triple que incluye la proteína transportadora ubicada en la parte más interna de la membrana citoplasmática, la proteína de fusión, presente en el espacio periplasmático y la porina de membrana externa (Li et al., 2015a). Este complejo funciona como antiporte de protón/droga, catalizando el flujo de salida de una amplia variedad de sustratos incluyendo antimicrobianos, pigmentos, sales biliares, detergentes y biocinas (Li \& Nikaido; Li et al., 2015a; Li et al., 2015b; Santajit \& Indrawattana, 2016). Estos transportadores secuestran drogas desde el citoplasma o desde el interior de la mem- brana interna y lo trasladan al espacio periplásmico. Para prevenir el reflujo hacia el interior de la célula, las bacterias Gram negativas implementan un sistema tripartito conformado por un transportador de membrana interna (ABC, MFS o RND), una proteína adaptadora periplasmática (MFP) y un canal de membrana externa (OMF). Mientras el acceso de la droga al pack tripartito ABC y MFS es desde el citoplasma hacia la membrana interna, el sistema RND lo hace desde el espacio periplásmico, a través de una conexión con la membrana externa o por extrusión desde el citoplasma por medio de simples transportadores, generando un sistema RND dependiente de simples componentes transportadores de la membrana interna (Masi et al.). Entre la familia RND, se destaca el sistema AcrAB-TolC presente en enterobacterias principalmente $E$. coli; que es uno de los sistemas más versátiles, debido a la capacidad de transporte de diversas sustancia nocivas permitiéndole resistir en ambientes hostiles (Piddock, 2006; Masi et al.). Este sistema reúne el transportador AcrB en el interior de la membrana, un canal de proteína en la membrana externa Tol C y un adaptador periplasmático, la proteína AcrA, distribuidos en proporción 3:6:3 (AcrA:AcrB:TolC). Cuando se activa el sistema de AcrAB/TolC, primero la proteína enlazadora se pliega sobre sí misma dando lugar a un estrecho contacto de las proteínas AcrB y TolC, entonces, una trayectoria de salida es proporcionada desde el interior hacia el exterior de la célula de modo que los agentes antimicrobianos puedan ser expulsados a través de este canal (Li \& Nikaido, 2009; Zhou et $a l$.). Este sistema aun cuando permite la eliminación de múltiples sustancias no transporta aminoglucósidos ni algunos $\beta$-lactámicos más hidrófobos, los cuales son transportados por el sistema AcrAD-Tol C. Otras bacterias como Pseudomonas aeruginosa utilizan otras bombas de salida, tal como Mex AB-OprM (Masi et al.). Las cepas mutantes de $P$. aeruginosa PA14, PA 1874 y PA 1877 sin la bomba de salida se vuelven más sensibles a los antibióticos tobramicina, gentamicina y ciprofloxacino (Tegos et al.; Zhou et al.).

Inhibición de la síntesis de la pared celular. Entre los mecanismos capaces de modificar la acción del fármaco, se menciona la hidrólisis enzimática, ya que muchos antibióticos tienen enlaces químicos tales como amidas y ésteres que son hidrolíticamente susceptibles (Borges et al.). Las bacterias producen enzimas que pueden impedir la actividad antibiótica por la orientación y la escisión de estos enlaces. Existe una línea de antibióticos conocidos como $\beta$ lactámicos, que reúne cinco grandes grupos de antibióticos de uso clínico, penicilinas, cefalosporinas, cefamicinas, monobactámicos y carbapenémicos, todos poseen una estructura común, el anillo $\beta$-lactámico, que puede ser hidrolizado por enzimas $\beta$-lactamasas (Sheldon). La familia Enterobacteriaceae asociadas al ambiente nosocomial, presenta una alta prevalencia para este tipo de mecanismo 
de resistencia, sin embargo está presente una amplia gama de bacterias desde Gram positivos a Gram negativos (Borges et al.; Santajit \& Indrawattana, 2016). En este grupo se destacan las $\beta$-lactamasas de espectro extendido (BLEE), con capacidad de resistencia a todas las penicilinas, monobactámicos y cefalosporinas de primera, segunda, tercera y cuarta generación, permitiendo el uso apenas de los $\beta$-lactámicos cefamicinas y carbapenémicos (Shaikh et al., 2015). Se les clasifica de diversas formas, algunos de ellos son según el mecanismo de acción existen cuatro grandes clases de estas enzimas $\beta$-lactamasas, las de clase A, C y D tienen serina en su sitio activo y las clase B son metaloenzimas (Sheldon). Según la estructura molecular y en la homología de sus secuencias de aminoácidos, las enzimas de clase A son del tipo penicilinasas y carbapenemasas, de clase B metalo- $\beta$-lactamasas (Zn), de clase $\mathrm{C}$ corresponde a Amp C o cefalosporinasas y las de clase D son oxacilinasas (Knothe et al., 1983).

Los mecanismos ya mencionados son una parte de las múltiples vías de resistencia cuya acción se centra en procesos externos o de la envoltura celular. $\mathrm{Al}$ revisar hacia el interior de la célula bacteriana, es posible encontrar otras forma de resistencia, como son la modificación de la composición química de los antibióticos, las modificaciones de procesos redox que ocurren a nivel intracelular (Borges et al.) y las proteínas de protección ribosomal (Sharkey et al., 2016).

Mecanismos de resistencia a nivel intracelular. A nivel intracelular se pueden distinguir otras formas de resistencia. Uno de los mecanismos menos estudiados tiene relación con cambios en el potencial redox, conocidos como procesos redox (Dzdic et al., 2008). Algunas bacterias pueden utilizar el potencial de óxido-reducción como mecanismo de evasión del efecto antimicrobiano, como ocurre con la oxidación del antibiótico tetraciclina por la enzima TetX presente en Streptomyces virginiae, agente productor de antibiótico M1 del tipo A estreptogramina virginiamicina. La bacteria se protege de su propio antibiótico mediante la reducción de un grupo cetona a un alcohol crítico (Dzdic et al.; Shaikh et al., 2015).

Por medio de enzimas modificadoras también, es posible inactivar la acción de los antibióticos, estas son denominadas grupos transfer o transferasas. Otorgan la capacidad de resistencia por sustitución química de moléculas resistentes, como son los grupos adenil, fosforil o acetil que se agregan en la periferia de la molécula antibiótica (Borges et al.). Esta modificación disminuye la capacidad de unión del fármaco al sitio objetivo (Shaikh et al.,). Las enzimas fosforiltransferasa, adeniltransferasas, nucleotidiltransferasas y acetiltransferasa neutralizan a los antibióticos aminoglucósidos, cloranfenicol, estreptogramina, macrólidos o rifampicina y se encuentran presentes en una gran diversidad de bacterias de importancia clínica tales como Staphylococcus aureus, Enterococcus faecalis y Streptococcus pneumoniae, Enterobacterias y bacilos Gram negativos no fermentadores (Borges et al.). Otro ejemplo de la modificación enzimática es la resistencia a ácido fusídico por síntesis de una acetiltransferasa en Enterobacterias y desacetilación por esterasas en cepas de Streptomyces (López Tricas, 2016). También participan acetiltranferasas en la resistencia a cloranfenicol y metilación de residuos de adenina en macrólidos (Zhou et al.). Las bacterias también son capaces de modificar el sitio blanco del fármaco, fenómeno conocido como modificación de puntos objetivos, en éste caso se altera el sitio de destino del antibiótico, impidiendo la unión adecuada del fármaco al receptor en el sitio blanco (Dzdic et al.). Es probable que esto suceda por mutaciones debido a que la bacteria no puede modificar en su totalidad estos sitios, muchas veces necesarios en otras funciones celulares (Shaikh et al.,).

Sistemas de Protección Ribosomal. Este tipo de sistemas dificulta la acción de antibióticos que actúan a nivel de la inhibición de la síntesis de proteínas (Dzdic et al.).

El ribosoma es la máquina de síntesis de las proteínas en la célula y por lo tanto juega un rol importante en la determinación del perfil de expresión génica global (Zhou et al.). Diversas clases de antibióticos actúan inhibiendo la síntesis de proteínas, sin embargo, las bacterias han desarrollado mecanismos de evasión de la acción de los antibióticos por medio de proteínas de protección ribosomal (RPPs, Ribosomal Protection Protein), (Dönhöfer et al., 2012; Zhou et al.; Sharkey et al., 2016). En los sistemas de protección ribosomal, los del tipo $\mathrm{ABC}-\mathrm{F}$ que incluyen a lsa(A), msr(A), optr(A) y vga(A) protegen a los ribosomas desplazando a los antibióticos por sistemas conjuntos con bombas de expulsión (Sharkey et al., 2016). Al parecer la acción antibiótica de tetraciclinas ejercen su acción mediante la inhibición de síntesis proteica bacteriana por su unión reversible a la unidad ribosomal 30S y de esta forma bloquean la unión del aminoacil-tRNA al sitio aceptor en el complejo ribosoma-RNA y también se une de forma reversible a la subunidad ribosomal 50S (Mosquito et al., 2011). Este mecanismo es regulado por genes específicos tales como tet $(\mathrm{M})$, tet $(\mathrm{O})$ en bacterias Gram positivos y tet $(\mathrm{M})$, tet $(\mathrm{O})$ tet $(\mathrm{S})$, tet $(\mathrm{W})$, tet $(\mathrm{Q})$, tet $(\mathrm{T}), \operatorname{Otr}(\mathrm{A})$ y tet $\mathrm{P}(\mathrm{B})$ en Gram negativos. Las proteínas codificadas por estos genes interactúan con proteínas ubicadas dentro del ribosoma, causando un cambio conformacional del sitio primario de unión de las tetraciclinas, promoviendo su liberación desde el ribosoma. (Roberts, 2005, Mosquito et al.; Dönhöfer et al.; Starosta et al., 2014). La resistencia a ácido fusídico por 
medio de mutaciones FUS-B impide la inhibición de la síntesis proteica, liberando estructuras secundarias mRNA secuestradas por efecto del fármaco. Con esto el ribosoma retorna a su estado conformacional estándar y la síntesis de proteínas prosigue (Roberts; Starosta et al.).

Modificación del sitio activo: Otra forma de resistencia se basa en la capacidad de las bacterias para generar sustancias metabólicas que compiten con el sitio activo del fármaco, como sucede con la resistencia a sulfonamidas por Staphylococcus aureus (Zhou et al.), mecanismo conocido como alteración de las vías de metabolitos. Por ejemplo, $S$. aureus, desarrolla resistencia a sulfonamidas por medio de un compuesto similar a PABA (ácido para-amino benzoico) (Zhou et al.). El PABA es un precursor del ácido fólico bacteriano. Las bacterias deben sintetizar su propio ácido fólico, conocido como vitamina B10. Algunos antibacterianos como las sulfonamidas compiten con el PABA por medio de la inhibición de la enzima dihidrofolato reductasa necesaria para el paso de dihidrofolato a tetrahidrofolato, cofactor necesario en la síntesis de DNA y proteínas. La resistencia bacteriana se presenta por mutación espontánea o transferencia de la misma a través de plásmidos, generando mutación de la dihidroteroato sintetasa, creando una vía metabólica alterna para la síntesis del ácido fólico y generando aumento en la capacidad de inactivar o destruir la droga y producción de un antagonista de la droga (Thiede et al., 2016; Gardeweg, 2012). Se destaca, igualmente, la alteración enzimática del sitio objetivo del fármaco, reduciendo la afinidad del antibiótico al sitio blanco; estos mecanismos también son regulados por enzimas eritromicina metilasas ribosomales que otorgan resistencia a macrólidos (Sheldon).

\section{Modificación genética}

Se debe considerar que las características genéticas de las bacterias favorecen el desarrollo de resistencia, ellas tienen un único cromosoma de modo que cualquier alteración en la hebra del DNA puede inducir cambios en su comportamiento. El genoma bacteriano tiene plasticidad, varía entre la estabilidad e inestabilidad, permitiéndole adaptación, protección de infecciones por fagos, capacidad de sobrevivencia y resistencia a antimicrobianos (Darmon \& Leach, 2014).

Los mecanismos de resistencia antibiótica están vinculados a la regulación génica, mediando todas las funciones asociadas a la evasión de la acción antibiótica, sin embargo con la finalidad de dar un orden estructural y fisiológico de la organización de la resistencia, se han seleccionado tres de estos procesos en esta categoría: mutación del gen, activación de genes reguladores específicos y de transcripción global.
Mutaciones del gen. Las mutaciones pueden proteger de los mecanismo de acción antibiótica; un ejemplo clásico son las enzimas, DNA girasa y topoisomerasa IV, que participan de la síntesis de DNA, las cuales presentan diversas mutaciones para no ser dañadas por fármacos como quinolonas (Zhou et al.). Ejemplo de ello son las mutaciones DNA topoisomerasas gyrA, gyrB y parC, responsables de la resistencia a fluoroquinolonas en Coxiella burnetii (Lima et al., 2013).

Regulación de la transcripción. Las modificaciones del DNA también pueden modular la funcionalidad de impermeabilidad de membranas, afectando la expresión de porinas o bombas de expulsión, generando resistencia (Hooper \& Jacoby, 2016) ya sea por mutaciones específicas como la inserción de elementos móviles (IS) que impiden la expresión del gen, a través de reguladores propios del operón o a través de regulación de multiresistencia. El principal regulador de multiresistencia es el operón MarA o gen RamA, Sox Srob (Chubiz \& Rao, 2011), que controlan resistencia a múltiples compuestos estructuralmente no relacionados, incluido antibióticos, desinfectantes y solventes orgánicos. Este operón está compuesto por tres unidades transcripcionales, un gen represor MarR, un gen regulador Mar A y un gen B que codifica una pequeña proteína de función desconocida (Randall \& Woodmard, 2002). Una proteína MarA induce y reprime más de 40 genes, importante actividad de fenotipo de resistencia y aumento de expresión de la bomba de expulsión AcrAB-TolC, por una vía independiente de AcrR y producción de RNA antisentido (MacF) que reduce la expresión de la proteína de membrana externa OmpF quedando activada y sobre expresada Mar A (Chubiz \& Rao).

Finalmente, un punto importante en los mecanismos de resistencia a todos los niveles moleculares es la diseminación de genes de resistencia antibiótica, la cual es mediada por elementos extracromosomales, transferidos horizontalmente entre bacterias (Million-Weaver \& Camps, 2014). Estos mecanismos se pueden transferir por medio de plásmidos, que a menudo presentan una gran facilidad de conjugación entre especies, lo que les adjudica importancia en la evolución de las bacterias por su fácil transmisión horizontal, generando resistencia a diferentes clases de antibióticos en un mismo elemento extra cromosómico (Zhou et al.). Uno de los principales elementos móviles de diseminación son los transposones o genes saltarines que pueden cambiar de posición dentro de un genoma, facilitando la transferencia de genes de resistencia entre especies (Ramos et al., 2014). Estos pueden ser conjugativos o no conjugativos (González et al., 2004). Un ejemplo es el transposón Tn3 de Tn1546 que confiere resistencia a glicopéptidos por síntesis de dispeptidoglicano en Enterococcus faecium. Otros transposones tales como Tn1547, Tn1549, Tn916, 
transposones conjugativos de la familia Tn916/Tn1545, la familia Tn21 y un grupo relativamente cerrado, confiere resistencia a los antimicrobianos vancomicina y tetraciclina (Zhou et al.). En Streptococcus pneumoniae la resistencia por metilación de la subunidad ribosómica $23 \mathrm{~S}$ está asociada con la inserción del gen erm(B) en un transposón de conjugación de la familia Tn916, el cual contiene el gen de resistencia a tetraciclina (tetM) y los genes de la integrasa (int) y excisasa (xis) que lo capacitan para realizar su propia transposición. Los transposones de esta familia incluyen el Tn6002, el Tn1545 (que transporta el gen de resistencia a kanamicina, aphA3), el Tn3872, el cual resulta de la inserción del Tn917 que, a su vez, contiene los genes TnpA (transposasa) y TnpR (resolvasa) en el transposón Tn916, y el Tn5253, un transposón compuesto conformado por la inserción del Tn5251 de la familia Tn916 en el elemento genético Tn5252, el cual transporta el marcador de resistencia a cloranfenicol (cat) y la integrasa int5252 (Ramos et al.).

La diseminación de genes también puede ser regulada por integrones o elementos de integración, pertenecientes a una familia de elementos genéticos potencialmente móviles capaces de integrar y expresar genes de resistencia a los antibióticos; funcionan como sistemas de captación de genes que permiten la captura y la expresión de genes exógenos eficientes, otorgando ventajas selectivas a las bacterias, principalmente Gram negativas (Gillings, 2014). Usualmente los integrones se componen de tres elementos necesarios para capturar genes exógenos, un gen intI que codifica una integrasa que media genes de integración de cassette y escisión a través de sitios específicos de recombinación RecA independiente, un sitio de recombinación attI donde se pueden encontrar una gran variedad de cassette genéticos que confieren resistencia a antimicrobianos y un promotor de orientación externa PCpant, capaz de direccionar la transcripción de los genes capturados desde los cassette genéticos (Barrantes \& Achí, 2016). En base a las secuencias de aminoácidos de lasintegrasas IntI se han descrito varios integrones (Barraud \& Ploy, 2015), reconociéndose más de nueve clases, siendo las de clase I las más frecuentemente descritas para resistencia a multidrogas en Gram negativos (Guzmán \& Alonso, 2010). Los integrones intercambian cassette genéticos por medio de integrasas catalizadoras sitio específico, recombinando cualquiera de ellas entre un sitio AttI y AttC o entre dos sitios AttC a partir de los cuales se inicia la excitación de los cassette genéticos (Barrantes \& Achí). Los cassette genéticos son descritos como pequeños elementos móviles conformados por una secuencia codificante y un sitio recombinante attC, reconocidos como integrasas attC. Se han reconocido más de 130 cassette genéticos que codifican resistencia a prácticamente todas las familias de antibióticos que incluyen antibióticos ß-lactámicos, aminoglicósidos, trimetroprim, sulfonamidas, fenicoles, tetraciclinas, rifampicina, eritromicina y, según informaciones recientes, a quinolonas (González et al.; Barrantes \& Achí).

Los integrones no pueden realizar autotransposición, por lo que utilizan como vehículos las secuencias de inserción, transposones y plásmidos conjugativos a los cuales se asocian para su transmisión en una misma especie o entre especies. Se han encontrado integrones de las clases 1 y 2 en plásmidos y transposones, los de clase 3 solamente en plásmidos, los de clase $4 \mathrm{o}$ "superintegrones" se han identificado principalmente en el cromosoma de Vibrio cholerae (González et al.). Reportes de Guzmán \& Alonso, señalan que en la región variable de integrones clase 1, más de 60 genes confieren resistencia a antimicrobianos de interés clínico, destacando en Klebsiella pneumoniae resistencia a los ß-lactámicos, aminoglucósidos y quinolonas (González et al.). En el caso de integrones que forman parte de un transposón, pueden transponerse desde el cromosoma hacia plásmidos y viceversa. Por su parte, los plásmidos conjugativos pueden transferirse intra o inter-especie, fenómeno genético particularmente importante por la presión selectiva existente a nivel nosocomial (González et al.).

\section{CONCLUSIONES}

La resistencia a antibióticos es un problema creciente a nivel mundial y lamentablemente el descubrimiento o aprobación de nuevas drogas no va a la misma velocidad, y los microrganismos multi-droga-resistentes ya no están limitados solamente al ambiente del hospital, si no que ahora son encontrados comúnmente en aislados de pacientes con infecciones de la comunidad. Este problema clínico se dificulta aún más debido a la alta plasticidad genética funcional de las bacterias siendo capaces de desarrollar mecanismos de resistencia de tipo intrínsecos y/o adaptativos, que se manifiestan a los diferentes niveles estructurales de la célula, donde muchos de estos mecanismos actúan coordinadamente entre sí, y poseen puntos de origen compartidos entre las funciones bacterianas. Las características adaptativas de los grupos bacterianos, también, determinan capacidades de resistencia a antimicrobianos por medio de mecanismos como son la formación de biopelículas y de consorcios quorum sensing, regulando la expresión de genes transmisibles por plásmidos, transposones e integrones. Cada uno de estos mecanismos demuestra patrones de comportamiento específicos siendo algunos más complejos que otros, variando según las características estructurales y fisiológicas de las bacterias y son generados en respuesta a estímulos que deben ser considerados en los procedimientos clínicos, industriales y ambientales, para lograr controlarlos. El estudio 
a nivel molecular y estructural de la resistencia antibiótica nos permitirá reconocer los puntos de riesgo en nuestras políticas de control de infecciones y realizar prevenciones más eficaces en la producción y diseminación de resistencia.

AGRADECIMIENTOS: Proyecto DI17-0116 y Proyecto DI15-0070. Claudia Troncoso y Andrés Santos agradecen a la Beca de Doctorado Nacional, Conicyt.

TRONCOSO, C.; PAVEZ, M.; SANTOS, A.; SAlAZAR, R. \& BARRIENTOS, L. Structural and physiological implications of bacterial cell in antibiotic resistance mechanisms. Int. J. Morphol., 35(4):1214-1223, 2017.

SUMMARY: The high adaptability of bacteria to hostile environments has favored antibacterial resistance development, impacting hospital and community healthcare worldwide. It has also affected disease control, limited therapeutic options and raised morbiditymortality rate. This resistance ability is mediated by structural and physiological factors of bacteria acting at both extracellular and cellular levels. The ability of bacterial populations in biofilm formation and regulation of cellular signal quorum sensing at the extracellular level, allows for the evasion of antibiotic action. At a cellular level, the performance and behavior of the cell wall and cell membrane is emphasized, mainly by regulating the expression of inlet channels or porins and/or expulsion pumps preventing access to, or inducing the outflow of antibiotics. Other mechanisms integrate modification of drug activity by hydrolysis or modification of the active site of the drug. Further into intracellular level, bacteria can change the oxidation/reduction processes; modify the target sites of the antibiotic and inactivate transfer groups. Bacteria can also modify the ribosomal subunits affecting the antibiotics which inhibit protein synthesis, and cause modifications of gene expression and genetic code that regulate the above mechanism. These may also generate adaptive changes and resistance to drugs and disinfectants. The aim of the present review is to describe the structural and physiological implications of bacterial cell in the mechanisms of antibiotic resistance. The study also considered the structural and physiological organization involved in the main mechanisms of antibiotic resistance in bacteria relevant to clinical healthcare.

KEY WORDS: Bacterial cell; Resistance; Antibiotics.

\section{REFERENCIAS BIBLIOGRÁFICAS}

Barrantes, K. \& Achí, R. The importance of integrons for development and propagation of resistance in Shigella: the case of Latin America. Braz. J. Microbiol., 47(4):800-6, 2016.

Barraud, O. \& Ploy, M. C. Diversity of class 1 integron gene cassette rearrangements selected under antibiotic pressure. J. Bacteriol., 197(13):2171-8, 2015.

Beceiro, A.; Tomás, M. \& Bou, G. Antimicrobial resistance and virulence: a successful or deleterious association in the bacterial world? Clin. Microbiol. Rev., 26(2):185-230, 2013.

Belas, R. Biofilms, flagella, and mechanosensing of surfaces by bacteria. Trends Microbiol., 22(9):517-27, 2014.
Billings, N.; Birjiniuk, A.; Samad, T. S.; Doyle, P. S. \& Ribbeck, K. Material properties of biofilms-a review of methods for understanding permeability and mechanics. Rep. Prog. Phys., 78(3):036601, 2015.

Borges, A.; Abreu, A. C.; Dias, C.; Saavedra, M. J.; Borges, F. \& Simões, M. New perspectives on the use of phytochemicals as an emergent strategy to control bacterial infections including biofilms. Molecules, 21(7):E877, 2016.

Chandra, H.; Bishnoi, P.; Yadav, A.; Patni, B.; Mishra, A. P. \& Nautiyal, A. R. Antimicrobial resistance and the alternative resources with special emphasis on plant-based antimicrobials-A review. Plants (Basel), 6(2):E16, 2017

Chubiz, L. M. \& Rao, C. V. Role of the mar-sox-rob regulon in regulating outer membrane porin expression. J. Bacteriol., 193(9):2252-60, 2011.

Cos, P.; Toté, K.; Horemans, T. \& Maes, L. Biofilms: an extra hurdle for effective antimicrobial therapy. Curr. Pharm. Des., 16(20):2279-95, 2010.

Cowan, S. W.; Schirmer, T.; Rummel, G.; Steiert, M.; Ghosh, R.; Pauptit, R. A.; Jansonius, J. N. \& Rosenbusch, J. P. Crystal structures explain functional properties of two E. coli porins. Nature, 358(6389):727-33, 1992.

Da Silva, G. J. \& Domingues, S. Insights on the horizontal gene transfer of carbapenemase determinants in the opportunistic pathogen Acinetobacter baumannii. Microorganisms, 4(3):E29, 2016.

Darmon, E. \& Leach, D. R. Bacterial genome instability. Microbiol. Mol. Biol. Rev., 78(1):1-39, 2014.

Delcour, A. H. Outer membrane permeability and antibiotic resistance. Biochim. Biophys. Acta, 1794(5):808-16, 2009.

Dönhöfer, A.; Franckenberg, S.; Wickles, S.; Berninghausen, O.; Beckmann, R. \& Wilson, D. N. Structural basis for TetM-mediated tetracycline resistance. Proc. Natl. Acad. Sci. U. S. A., 109(42):16900-5, 2012.

Donné, J. \& Dewilde, S. The challenging world of biofilm physiology. Adv. Microb. Physiol., 67:235-92, 2015.

Dzdic, S.; Suskcovic, J. \& Kos, B. Antibiotic resistance in bacteria. Food Technol. Biotechnol., 46(1):11-21, 2008.

Erickson, K. E.; Otoupal, P. B. \& Chatterjee, A. Gene expression variability underlies adaptive resistance in phenotypically heterogeneous bacterial populations. ACS Infect. Dis., 1(11):555-67, 2015.

Findlay, J.; Hamouda A.; Dancer, S. J. \& Amyes, S. G. Rapid acquisition of decreased carbapenem susceptibility in a strain of Klebsiella pneumoniae arising during meropenem therapy. Clin. Microbiol. Infect., 18(2):140-6, 2012.

Frye, J. G. \& Jackson, C. R. Genetic mechanisms of antimicrobial resistance identified in Salmonella enterica, Escherichia coli, and Enteroccocus spp. isolated from U.S. food animals. Front. Microbiol., 4:135, 2013.

García-Fernández, A.; Miriagou, V.; Papagiannitsis, C. C.; Giordano, A.; Venditti, M.; Mancini, C. \& Carattoli, A. An ertapenem-resistant extended-spectrum-beta-lactamase-producing Klebsiella pneumoniae clone carries a novel OmpK36 porin variant. Antimicrob. Agents Chemother., 54(10):4178-84, 2010

Gardeweg, M. L. Manual Microdiagnóstica. Santiago de Chile, Laboratorio Linsan S. A. M., 2012.

Gill, E. E.; Franco, O. L. \& Hancock, R. E. Antibiotic adjuvants: diverse strategies for controlling drug-resistant pathogens. Chem. Biol. Drug Des., 85(1):56-78, 2015.

Gillings, M. R. Integrons: past, present, and future. Microbiol. Mol. Biol. Rev., 78(2):257-77, 2014.

González, R. G.; Mella, M. S.; Zemelman, Z. R.; Bello, T. H. \& Domínguez, Y. M. Integrons and resistance gene cassettes: structure and role against antimicrobials. Rev. Med. Chile, 132(5):619-26, 2004.

Guzmán, M. \& Alonso, G. Characterization of the variable region within class 1 integrons in Klebsiella pneumoniae nosocomials strains. Rev. Med. Chile, 138(3):322-9, 2010.

Hooper, D. C. \& Jacoby, G. A. Topoisomerase inhibitors: fluoroquinolone mechanisms of action and resistance. Cold Spring Harbor Perspect. Med., 6(9), 2016.

http://www.jano.es/ficheros/sumarios/1/0/1660/28/ 1v0n1660a13108119pdf001.pdf 
Jayaraman, A. \& Wood, T. K. Bacterial quorum sensing: signals, circuits, and implications for biofilms and disease. Ann. Rev. Biomed. Eng., 10:14567, 2008.

Jefferson, K. K.; Goldmann, D. A. \& Pier, G. B. Use of confocal microscopy to analyze the rate of vancomycin penetration through Staphylococcus aureus biofilms. Antimicrob. Agents Chemother., 49(6):2467-73, 2005.

Knothe, H.; Shah, P.; Krcmery, V.; Antal, M. \& Mitsuhashi, S. Transferable resistance to cefotaxime, cefoxitin, cefamandole and cefuroxime in clinical isolates of Klebsiella pneumoniae and Serratia marcescens. Infection, 11(6):315-7, 1983.

Krishnamurthy, M.; Moore, R. T.; Rajamani, S. \& Panchal, R. G. Bacterial genome engineering and synthetic biology: combating pathogens. B. $M$. C. Microbiol., 16(1):258, 2016.

LaSarre, B. \& Federle, M. J. Exploiting quorum sensing to confuse bacterial pathogens. Microbiol. Mol. Biol. Rev., 77(1):73-111, 2013.

Lebeaux, D.; Ghigo, J. M. \& Beloin, C. Biofilm-related infections: bridging the gap between clinical management and fundamental aspects of recalcitrance toward antibiotics. Microbiol. Mol. Biol. Rev., 78(3):510 43, 2014

Lewis, K. Riddle of biofilm resistance. Antimicrob. Agents Chemother, 45(4):999-1007, 2001.

Li, X. Z. \& Nikaido, H. Efflux-mediated drug resistance in bacteria: an update. Drugs, 69(12):1555-623, 2009.

Li, X. Z.; Plésiat, P. \& Nikaido, H. The challenge of efflux-mediated antibiotic resistance in Gram-negative bacteria. Clin. Microbiol. Rev., 28(2):337418, 2015a.

Li, Y.; Zheng, B.; Li, Y.; Zhu, S.; Xue, F. \& Liu, J. Antimicrobial susceptibility and molecular mechanisms of fosfomycin resistance in clinical Escherichia coli isolates in mainland China. PloS One, 10(8):e0135269, 2015b.

Lima, T. B.; Pinto, M. F.; Ribeiro, S. M.; de Lima, L. A.; Viana, J. C.; Gomes Júnior, N.; Cândido, E. de S.; Dias, S. C. \& Franco, O. L. Bacterial resistance mechanism: what proteomics can elucidate. FASEB J. 27(4):1291-303, 2013.

López Tricas, M. Ácido Fusídico. Informe Técnico. Info Farmacia.com, 2016. Disponible en: http://www.info-farmacia.com/medico-farmaceuticos/informes-tecnicos/acido-fusidico-informe-tecnico

Martínez, J. A. \& Sánchez, F. Mecanismo de acción de los antibióticos. JANO, (1660):28-34, 2007. Disponible en:

Masi, M.; Réfregiers, M.; Poss, K. M. \& Pagès, J. M. Mechanisms of envelope permeability and antibiotic influx and efflux in Gram-negative bacteria. Nat. Microbiol., 2:17001, 2017.

Million-Weaver, S. \& Camps, M. Mechanisms of plasmid segregation: have multicopy plasmids been overlooked? Plasmid, 75:27-36, 2014.

Mosquito, S.; Ruiz, J.; Bauer, J. L. \& Ochoa, T. J. Mecanismos moleculares de resistencia antibiótica en Escherichia coli asociadas a diarrea. Rev. Peru. Med. Exp. Salud Pública, 28(4):648-56, 2011.

Organización Mundial de la Salud (OMS). Resistencia a los Antibióticos. Génova, Organización Mundial de la Salud, 2017. Disponible en: http:// www.who.int/mediacentre/factsheets/antibiotic-resistance/es/

Organización Mundial de la Salud (OMS). Resistencia a los Antimicrobianos. Proyecto de Plan de Acción Mundial sobre la Resistencia a los Antimicrobianos. Génova, 68 ${ }^{\mathrm{a}}$ Asamblea Mundial de la Salud A68/20 Punto 15.1 del Orden del Día Provisional, 2015. Disponible en: http:// apps.who.int/gb/ebwha/pdf_files/WHA68/A68_20-sp.pdf

Pagès, J. M.; James, C. E. \& Winterhalte, M. The porin and the permeating antibiotic: a selective diffusion barrier in Gram-negative bacteria. Nat. Rev. Microbiol., 6(12):893-903, 2008.

Peterson, B. W.; He, Y.; Ren, Y.; Zerdoum, A.; Libera, M. R.; Sharma, P. K.; van Winkelhoff, A. J.; Neut, D.; Stoodley, P.; van der Mei, H. C. \& Busscher, H. J. Viscoelasticity of biofilms and their recalcitrance to mechanical and chemical challenges. FEMS Microbiol. Rev., 39(2):23445, 2015.

Peyyala, R. \& Ebersole, J. L. Multispecies biofilms and host responses: "discriminating the trees from the forest". Cytokine, 61(1):15-25, 2013.

Picão, R. C.; Andrade, S. S.; Nicoletti, A. G.; Campana, E. H.; Moraes, G. C.;
Mendes, R. E.; \& Gales, A. C. Metallo-beta-lactamase detection: comparative evaluation of double-disk synergy versus combined disk tests for IMP-, GIM-, SIM-, SPM-, or VIM-producing isolates. J. Clin. Microbiol., 46(6):2028-37, 2008.

Piddock, L. J. Clinically relevant chromosomally encoded multidrug resistance efflux pumps in bacteria. Clin. Microbiol. Rev., 19(2):382-402, 2006.

Que, Y. A.; Hazan, R.; Strobel, B.; Maura, D.; He, J.; Kesarwani, M.; Panopoulos, P.; Tsurumi, A.; Giddey, M.; Wilhelmy, J.; Mindrinos, M. N. \& Rahme, L. G. A quorum sensing small volatile molecule promotes antibiotic tolerance in bacteria. PLoS One, 8(12):e80140, 2013.

Ramos, V.; Duarte, C.; Díaz, A. \& Moreno, J. Elementos genéticos móviles asociados con resistencia a eritromicina en aislamientos de Streptococcus pneumoniae en Colombia. Biomédica, 34(Supl.1):209-16, 2014.

Randall, L. P. \& Woodward, M. J. The multiple antibiotic resistance (mar) locus and its significance. Res. Vet. Sci., 72(2):87-93, 2002.

Roberts, M. C. Update on acquired tetracycline resistance genes. FEMS Microbiol. Lett., 245(2):195-203, 2005.

Sager, M.; Benten, W. P.; Engelhardt, E.; Gougoula, C. \& Benga, L. Characterization of Biofilm Formation in [Pasteurella] pneumotropica and [Actinobacillus] muris Isolates of Mouse Origin. PLoS One, 10(10):e0138778, 2015

Santajit, S. \& Indrawattana, N. Mechanisms of antimicrobial resistance in ESKAPE pathogens. BioMed Res. Int., 2016:2475067, 2016.

Shaikh, S.; Fatima, J.; Shakil, S.; Mohd, S.; Rizvi, S. M. \& Kamal, M. A. Antibiotic resistance and extended spectrum beta-lactamases: Types, epidemiology and treatment. Saudi J. Biol. Sci., 22(1):90-101, 2015.

Sharkey, L. K. R.; Edwards, T. A. \& O'Neill, A. J. ABC-F proteins mediate antibiotic resistance through ribosomal protection. mBio, 7(2):e01975$15,2016$.

Sheldon, A. T. Jr. Antibiotic resistance: a survival strategy. Clin. Lab. Sci., 18(3):170-80, 2005.

Singh, R.; Ray, P.; Das, A. \& Sharma, M. Penetration of antibiotics through Staphylococcus aureus and Staphylococcus epidermidis biofilms. $J$. Antimicrob. Chemother., 65(9):1955-8, 2010.

Starosta, A. L.; Lassak, J.; Jung, K. \& Wilson, D. N. The bacterial translation stress response. FEMS Microbiol. Rev., 38(6):1172-201, 2014.

Tegos, G. P.; Haynes, M.; Strouse, J. J.; Khan, M. M.; Bologa, C. G.; Oprea, T. I. \& Sklar, L. A. Microbial efflux pump inhibition: tactics and strategies. Curr. Pharm. Des., 17(13):1291-302, 2011.

Thiede, J. M.; Kordus, S. L.; Turman, B. J.; Buonomo, J. A.; Aldrich, C. C.; Minato, Y. \& Baughn, A. D. Targeting intracellular p-aminobenzoic acid production potentiates the anti-tubercular action of antifolates. Sci. Rep., 6:38083, 2016.

Zhou, G.; Shi, Q. S.; Huang, X. M. \& Xie, X. B. The three bacterial lines of defense against antimicrobial agents. Int. J. Mol. Sci., 16(9):21711-33, 2015.

\section{Dirección para correspondencia:}

Dra. Leticia Barrientos Díaz

Laboratorio de Biología Molecular Aplicada

Departamento de Ciencias Básicas

Facultad de Medicina

Universidad de La Frontera

Temuco

CHILE

\section{E-mail: leticia.barrientos@ufrontera.cl}

Recibido : 07-07-2017

Aceptado: $30-08-2017$ 